\title{
Effects of shrub presence and shrub species on ground beetle assemblages (Carabidae, Curculionidae and Tenebrionidae) in a sandy desert, northwestern China
}

\author{
JiLiang LIU ${ }^{1,2^{*}}$, WenZhi ZHAO ${ }^{1,2}$, FengRui LI, \\ ${ }^{1}$ Linze Inland River Basin Research Station, Chinese Ecosystem Research Network, Lanzhou 730000, China; \\ ${ }^{2}$ Laboratory of Ecohydrology and Integrated River Basin Science, Cold and Arid Regions Environmental and Engineering \\ Research Institute, Chinese Academy of Sciences, Lanzhou 730000, China
}

\begin{abstract}
Shrub presence has an important effect on the structuring of ground beetles in desert ecosystems. In this study, in order to determine how shrubs and different species influence ground beetle assemblages in a sandy desert scrubland dominated by two different shrub species, namely Calligonum mongolicum and Nitraria sphaerocarpa, we sampled the ground beetles using pitfall traps during spring, summer and autumn in 2012. At the community level, the activity density of the ground beetles was shown to be significantly higher under shrubs than in intershrub bare habitats in spring; but an opposite pattern occurred in autumn, suggesting the presence of season-specific shrub effects on the activity density of the ground beetles. Meanwhile, at the trophic group level, the activity density and species richness of predators were significantly greater under shrubs than in intershrub bare habitats in spring, whereas an opposite trend occurred on the activity density in autumn. N. sphaerocarpa shrubs had a positive effect on the activity density of herbivores in the three seasons, and C. mongolicum shrubs had a positive effect on the activity density of detritivores in spring and autumn. At the species level, more Microdera sp. was captured under shrubs than in intershrub bare habitats in spring. During the same time, we also found that $C$. mongolicum shrubs had a positive effect on Blaps gobiensis in spring, Carabus sp. in autumn, and Tentyria sp. in spring and autumn, and $N$. sphaerocarpa shrubs had a positive effect on Cyphogenia chinensis, Sternoplax setosa in spring and summer, and Curculionidae sp. 1 in summer and autumn. The study results suggest that shrub presence, shrub species and season variation are important factors for ground beetle assemblages in this desert ecosystem, but the responses of beetles differed among trophic and taxonomic levels.
\end{abstract}

Keywords: Calligonum mongolicum, Nitraria sphaerocarpa, ground beetle assemblages, sandy desert ecosystem, Heihe River basin

Citation: JiLiang LIU, WenZhi ZHAO, FengRui LI. 2015. Effects of shrub presence and shrub species on ground beetle assemblages (Carabidae, Curculionidae and Tenebrionidae) in a sandy desert, northwestern China. Journal of Arid Land, 7(1): 110-121. doi: 10.1007/s40333-014-0040-6

Arid and semiarid regions cover more than one-third of the Earth's surface, making these systems the largest biome in the world (Schlesinger, 1991; Reynolds, 2007). Shrubland is a widely distributed vegetation type in arid and semiarid ecosystems both in China and elsewhere in the world (Polis, 1991; Aguiar and Sala, 1999). Shrub patches consisting of one or several shrubs are restricted by soil moisture in arid desert ecosystems (Aguiar and Sala, 1999). These shrubs, with their root systems and shading canopies, can create nutrient-rich patches within a low-nutrient matrix (i.e. "fertile islands"), and can modify the environment nearby, thus potentially greatly affecting the biota in these ecosystems (Zhao et al., 2007; Eldridge et al., 2011). In addition, shrubs may also play vital roles in maintaining ground-dwelling and soil arthropod diversity in these ecosystems (Mazía et al., 2006; Shelef and Groner, 2011; Liu et al., 2012; Li et al., 2013;

"Corresponding author: JiLiang LIU (E-mail: liuj1707@1zb.ac.cn)

Received 2014-02-24; revised 2014-07-14; accepted 2014-08-13

(C) Xinjiang Institute of Ecology and Geography, Chinese Academy of Sciences, Science Press and Springer-Verlag Berlin Heidelberg 2015 
Zhao and Liu, 2013). There are at least three functional roles of shrubs which may provide potential mechanisms influencing the activity of arthropod abundance and distribution in an arid ecosystem, one of which is the shading and associated reduction in soil temperature, solar radiation extremes and shelters, and provide refuge for ground-dwelling and soil arthropod against predators (Parmenter and Macmahon, 1988; Valiente-Banuet and Ezcurra, 1991; Ayal and Merk1, 1994; López-Pintor et al., 2006; Mazía et al., 2006). The second potential mechanism is the rainfall-intercepting effect of the shrub canopy (Haworth and McPherson, 1995; Li et al., 2008), which allows the soil to store more rain water around shrubs. The third potential mechanism is the resource-capturing effect via intercepting plant litter and wind-dispersed shrub seeds from nearby areas (Ben-Natan et al., 2004; Bullock and Moy, 2004). Consequently, a combination of these effects is likely to lead to outcomes such as relatively stable substrate, mild microclimate and high resource availability around shrubs, thereby facilitating the colonization or activity of arthropods by means of providing food resources, oviposition sites, shelters or refuges against predators (Parmenter et al., 1989; Antvogel and Bonn, 2001; Sanchez and Parmenter, 2002; Mazía et al., 2006; Watson et al., 2011).

Ground beetles (Coleoptera) are common species and abundant in all arid and semiarid ecosystems (Parmenter et al., 1989; Gaston, 1991; Stapp, 1997; Mazía et al., 2006; Gobbi and Fontaneto, 2008; Liu et al., 2010; Yang et al., 2010). This group is primarily comprised generalist detritivorous species, predators and herbivorous species and occupies a tremendous variety of microhabitats across a wide array of spatial and temporal scales in arid and semiarid regions, thereby potentially playing vital roles in detritus-based food webs (Polis, 1991; Kremen et al., 1993; Moore et al., 2004; Barton et al., 2009; Bang et al., 2012). Ground beetles also exhibit a wide variety of morphological, ecological, physiological and behavioral adaptations to the harsh desert conditions (Ren and $\mathrm{Yu}$, 1999; Cloudsley-Thompson, 2001; Zotov and Alpatov, 2005; Bartholomew and Ebeid, 2011). Therefore, ground beetles sensitively reflect human impact, landuse and climate in arid ecosystems (Lövei and Sunderland, 1996; Rykken et al., 1997; Woodcock et al.,
2005; Barton et al., 2009). In general, the assembly of ground beetle communities is considered to be driven by both biotic (e.g. vegetation type, plant community composition and species identity; Bardgett et al., 1999; Crist et al., 2006; Bezemer et al., 2010; Yang et al., 2010) and abiotic factors (e.g. soil texture, temperature and water availability; Fallaci et al., 1997; Stapp, 1997; Antvogel and Bonn, 2001; Botes et al., 2007; Pétillon et al., 2008; Sackmann and Flores, 2009). At present, most researches regarding the impacts of landscape, plant community, vegetation type and diversity on ground beetle assemblages have been performed at large and medium scales, but little research has been conducted at a small spatial scale, i.e. on a single shrub or a small plot of shrubs.

Moreover, according to our knowledge the combined effects of shrub presence and different species on the structure of ground beetle assemblages in arid desert ecosystems have not been previously studied. Several recent studies performed in the arid and semiarid regions of China have demonstrated that the degradation or loss of shrubland habitats has a significant influence on the abundance, species richness and community structure of ground beetles (Liu et al., 2010; Yang et al., 2010; Yin et al., 2010; He et al., 2011; Liu et al., 2012; Zhao and Liu, 2013). To improve our understanding of the shrub presence and species in structuring ground beetle communities, we conducted a field investigation in a sandy desert in the central parts of the Heihe River basin, northwestern China. In the current study, we use two dominant native shrub species, Calligonum mongolicum (Polygonaceae) and Nitraria sphaerocarpa (Zygophyllaceae), occurring widely in the sandy desert as a model system. The aims of this study were to determine how shrubs and their species identity influence the spatial distribution of ground-dwelling beetles, and to assess whether the response of beetles to the presence and species of shrubs differed among trophic and species levels. We tested two hypotheses: (1) Do the presence and species of shrub influence the activity density and species richness of ground beetles? (2) And do these effects vary among trophic guilds and species? We hypothesized that shrub presence and species identity would affect the spatial distribution and diversity of the beetle community, by altering spatial configuration of habitat use of ground beetles, but their effects 
would vary among different trophic groups and species. An understanding of the possible dependence of ground beetles on shrub presence and species is required for an efficient protection of shrub vegetation and its species diversity in arid ecosystems.

\section{Materials and methods}

\subsection{Study area}

This study was conducted in a sandy desert ecosystem in the middle reaches of the Heihe River $\left(39^{\circ} 21^{\prime} \mathrm{N}\right.$, $100^{\circ} 09^{\prime} \mathrm{E}$; $1,380 \mathrm{~m}$ asl), the Heihe River basin being the second largest inland river basin in the arid regions of northwestern China. The site has a temperate continental climate. The annual average temperature is $7.6^{\circ} \mathrm{C}$, with the minimum monthly mean temperature of $-10.7^{\circ} \mathrm{C}$ in January and the maximum monthly mean temperature of $23.8^{\circ} \mathrm{C}$ in July. The average annual precipitation over the past 30 years is $117 \mathrm{~mm}$, with $75 \%$ of rainfall falling between June and September (He et al., 2007). The soil in the study area is dominated by aeolian sandy soil, according to the Chinese classification system, with $19.89 \%$ coarse sand content $(>0.25 \mathrm{~mm}), 78.98 \%$ medium and fine sand content $(0.05-0.25 \mathrm{~mm})$ and $1.13 \%$ silt and clay content $(<0.05 \mathrm{~mm})$. The soil bulk density is $1.56 \mathrm{~g} / \mathrm{cm}^{3}$, and $\mathrm{pH}$ is 9.24 . The soil organic carbon, total nitrogen and total phosphorus concentrations are $0.69,0.011$ and $0.25 \mathrm{~g} / \mathrm{kg}$, respectively (Liu et al., 2010).

Vegetation at the shrubland site was dominated by two xerophytic shrub species, namely C. mongolicum and $N$. sphaerocarpa, together with herbaceous species such as Agriophyllum squarrosum (L.) Moq., Bassia dasyphylla Kuntze, Halogeton arachnoideus Moq., Echinops gmelini Turcz. and Pugionium calcaratum Kom. The vegetation cover was $13.9 \%$ and the density of the shrubs was 2,420 plants $/ \mathrm{km}^{2}$ for $C$. mongolicum and 2,030 plants $/ \mathrm{km}^{2}$ for N. sphaerocarpa in the studied shrubland patch. Moreover, the density of herbaceous vegetation was 85.2 pla$\mathrm{nts} / \mathrm{m}^{2}$, and the amount of plant litter is $11.1 \mathrm{~g} / \mathrm{shrub}$ under C. mongolicum and $5.1 \mathrm{~g} / \mathrm{shrub}$ under $N$. sphaerocarpa.

\subsection{Beetle sampling}

In order to determine the influence of shrubs and species identity on the distribution and diversity of ground beetles, we established three $200 \mathrm{~m} \times 200 \mathrm{~m}$ sampling sites located at least $500 \mathrm{~m}$ apart (Ziesche and Roth, 2008) in the shrubland patch which had been used as a permanent vegetation monitoring site by the Linze Inland River Basin Research Station, Chinese Ecosystem Research Network. Four adult individuals of $C$. mongolicum of similar sizes (76.6 $\mathrm{cm}$ in height and $94.4 \mathrm{~cm}$ in canopy width, hereafter referred to as "mongolicum plots") and four adult individuals of $N$. sphaerocarpa of similar sizes $(50.4 \mathrm{~cm}$ in height and $72.8 \mathrm{~cm}$ in canopy width, hereafter referred to as "sphaerocarpa plots"), as well as four open bare ground plots between shrubs, were selected in each of the sampling sites (hereafter referred to as "bare plots"). The distance between the shrubs that were sampled within a plot was $>6 \mathrm{~m}$, to avoiding autocorrelation between the traps (Mazía et al., 2006). Pitfall traps $(8 \mathrm{~cm}$ in diameter, $10 \mathrm{~cm}$ in depth) filled with approximately $70 \mathrm{~mL}$ of $70 \%$ ethanol solution were buried flush with the ground surface under canopies of both shrubs, as well as in the intershrub bare areas (the distance to the nearest shrub sampled was $>5 \mathrm{~m}$ ). Pitfall traps were placed in three different microhabitats, namely mongolicum, sphaerocarpa and bare plots. We thus had 12 traps from each plot type, and a total of 36 traps from the three plot types. Sampling was conducted in spring (6-20 May), summer (4-18 July) and autumn (8-22 September), which corresponds to the main period of ground beetle activity in our study system (Liu et al., 2010). Each of the three sampling periods consisted of 15 consecutive days, and all traps were checked every three days during each sampling period. We added ethanol solution during the 15-day sampling period when the solution had evaporated completely. Captured beetle specimens (preserved in $75 \%$ ethyl alcohol) were counted and identified to the species level according to the method described by Ren and $\mathrm{Yu}$ (1999) and Zheng and Gui (2000). We also categorized beetles into the categories of carnivores, detritivores and herbivores based on their diets (Ren and Yu, 1999; Zheng and Gui, 2000; Zhang et al., 2002). In the following section, "abundance" refers to the activity density or catch rate of beetles, and "richness" 
refers to the number of species in a sample.

\subsection{Plant characteristics and physical environment}

The vegetation covers for woody and herbaceous plant layers at each sampling site were surveyed in late August 2012, at the peak growing season of plant community. In each sampling site, herbaceous cover was visually estimated by using five $1-\mathrm{m}^{2}$ quadrats. The shrub cover was measured using the line-intercept method with 20 interception lines at an interval of $5 \mathrm{~m}$ at each sampling sites. The total vegetation cover was the combined percentage cover of woody and herbaceous vegetation. The amount of plant litter at each shrub microhabitats was also measured using the quadrat method in early October 2012.

At each sampling plot, four soil cores $(5 \mathrm{~cm}$ in diameter, $20 \mathrm{~cm}$ in depth) were taken using an auger. These four cores were pooled and mixed thoroughly to form one composite soil sample (with a total of 12 samples for each of the three microhabitat types) to analyze the soil texture. The particle size distribution was determined using a Microtrac S3500 Particle Size Analyzer (Microtrac Inc., USA) by dividing the soil into three particle sizes: coarse sand $(2.00-0.05 \mathrm{~mm})$, silt $(0.05-0.001 \mathrm{~mm})$ and clay $(<0.001 \mathrm{~mm})$, which were expressed as a percentage of soil weight.

\subsection{Data analysis}

We classified all collected beetles into three trophic groups (detritivores, herbivores and predators) basing on the method described in previous references (Lawrence and Britton, 1991; Ren and Yu, 1999; Zheng and Gui, 2000; Zhang et al., 2003). Not all beetles could be identified to the species level, but all taxa are referred to as "species" below for convenience reasons. To determine the community, trophic- and population-level responses of ground beetles to the shrub presence and species identity, we calculated the total abundance (total number of beetles per trap) at the community level and total species richness (total number of species found in per trap). At the trophic group level, the total number of ground beetles captured per trap for each of the three trophic groups was also calculated. At the species level, the total number of abundantly caught species was also calculated (Anatolica sp., Blaps gobinesis, Carabus sp., Curculionidae sp.1, Cyphogenia chinensis, Sternoplax setosa,
Tentyria sp. and Microdera sp.). We performed a two-way ANOVA using SPSS 19.0 for Windows (SPSS Inc, Chicago, Illinois) to determine the effects of plot type and sampling period (spring, summer or autumn) as well as their interaction on the activity density and species richness of all species, the three trophic groups, and the activity-density of abundant species. Tukey's post-hoc tests were used to compare variation in the response variables among seasons and plot types. Furthermore, one-way ANOVA and Tukey's post-hoc tests were also used to determine the differences in the measured environmental variables (coarse sand content, fine sand content and silt plus clay content) among the plot types.

A perMANOVA (Permutation based MANOVA, perMANOVA) was used to test whether the community composition of ground-dwelling beetles (based on Bray-Curtis dissimilarity) varied according to season, plot type and their interaction (PRIMER software; Anderson et al., 2008). We calculated the dissimilarity among seasons and microhabitats using species activity-density data for the community. $P$ values were then obtained using 999 permutations.

\section{Results}

\subsection{The response of community composition to the presence and species of shrubs}

A total of 11,417 adult beetles were captured from the three microhabitat types during the three sampling periods (Table 1). The collected beetles represented 13 species from the families of Carabidae, Curculionidae and Tenebrionidae. Next, eight most abundantly captured species were selected for a species-level analysis: Anatolica sp., Blaps gobinesis, Carabus sp., Curculionidae sp. 1, Cyphogenia chinensis, Sternoplax setosa, Tentyria sp. and Microdera sp.

The perMANOVA tests showed significant effects of season $\left(F_{2,107}=315.73, P<0.001\right)$, plot type $\left(F_{2,107}=\right.$ 41.01, $P<0.001)$ and their interaction $\left(F_{4,107}=38.47\right.$, $P<0.001)$ on the community composition of grounddwelling beetles. Pairwise comparisons showed marked differences in communities between the mongolicum and sphaerocarpa plots $(t=7.77, P<$ $0.001)$, mongolicum and bare plots $(t=5.64, P<0.001)$, and sphaerocarpa and bare plots $(t=4.54, P<0.001)$. 
Table 1 Ground beetles species recorded in three plots (C. mongolicum, $N$. sphaerocarpa and bare plots) in a sandy desert of northwestern China

\begin{tabular}{|c|c|c|c|c|c|c|c|c|}
\hline Family/Species name & $\begin{array}{l}\text { C. mongolicum } \\
\text { plot }\end{array}$ & $\begin{array}{l}\text { N. sphaero- } \\
\text { carpa plot }\end{array}$ & Bare plot & $\begin{array}{c}\text { Total } \\
\text { abundance }\end{array}$ & $\begin{array}{c}\text { Relative } \\
\text { abundance (\%) }\end{array}$ & $\begin{array}{r}\text { Body length } \\
(\text { mean } \pm \text { SE) }\end{array}$ & $\begin{array}{l}\text { Feeding } \\
\text { guilds }\end{array}$ & Activity \\
\hline \multicolumn{9}{|l|}{ Carabidae } \\
\hline Carabus sp. & 39 & 17 & 46 & 102 & 0.89 & $23.72 \pm 0.85$ & Carnivores & Night \\
\hline Carabidae sp.1 & 20 & 26 & 9 & 55 & 0.48 & $11.34 \pm 0.35$ & Carnivores & Night \\
\hline Carabidae sp.2 & 6 & 13 & 4 & 23 & 0.20 & $8.62 \pm 0.21$ & Carnivores & Night \\
\hline \multicolumn{9}{|l|}{ Curculionidae } \\
\hline Curculionidae sp.1 & 68 & 1,596 & 831 & 2,495 & 21.85 & $12.14 \pm 0.32$ & Herbivores & Day \\
\hline Curculionidae sp.2 & 18 & 0 & 10 & 28 & 0.25 & $16.14 \pm 0.78$ & Herbivores & Day \\
\hline Curculionidae sp.3 & 7 & 0 & 0 & 7 & 0.06 & $6.14 \pm 0.54$ & Herbivores & Day \\
\hline \multicolumn{9}{|l|}{ Tenebrionidae } \\
\hline Anatolica sp. & 47 & 23 & 34 & 104 & 0.91 & $14.57 \pm 0.85$ & Detritivores & Day \\
\hline Blaps gobiensis & 44 & 40 & 62 & 146 & 1.28 & $21.19 \pm 0.91$ & Detritivores & Night \\
\hline Cyphogenia chinensis & 71 & 139 & 79 & 289 & 2.53 & $20.10 \pm 1.61$ & Herbivores & Night \\
\hline Sternoplax setosa & 212 & 337 & 221 & 770 & 6.74 & $18.85 \pm 0.48$ & Herbivores & Night \\
\hline Tentyria sp. & 2,725 & 2,287 & 2,257 & 7,269 & 63.67 & $12.77 \pm 0.73$ & Detritivores & Day \\
\hline $\begin{array}{l}\text { Mantichorula } \\
\text { semenowi }\end{array}$ & 5 & 0 & 11 & 16 & 0.14 & $14.50 \pm 0.42$ & Detritivores & Day \\
\hline Microdera sp. & 56 & 48 & 9 & 113 & 0.99 & $9.75 \pm 0.50$ & Detritivores & Night \\
\hline
\end{tabular}

Note: Body size data taken from 7-10 individuals per species.

The two-way ANOVA tests showed that plot type had a significant effect on the abundance of ground beetles, but did not markedly affect richness (Table 2). However, there were significant interactions between plot type and season on the abundance of grounddwelling beetles, indicating that the effect of plot type varied among the seasons (Table 2). Separate analyses for each season showed that positive effect of shrubs on the abundance of ground-dwelling beetles was significant only in spring, whereas the identity of shrub species affected the abundance only in autumn (Fig. 1). More ground beetles were captured under shrubs than in bare plots in spring, and in addition more ground beetles were captured in the sphaerocarpa than in the mongolicum plots, but this pattern was significant only in autumn (Fig. 1).

Table 2 Results of two-way ANOVA for the effects of season (spring, summer and autumn) and plot type (mongolicum, sphaerocarpa and bare plot) and their interaction on the abundance and richness of ground beetles as well as three trophic groups

\begin{tabular}{|c|c|c|c|}
\hline & Season $\left(F_{2,107}\right)$ & Plot type $\left(F_{2,107}\right)$ & Season $\times$ Plot type $\left(F_{4,107}\right)$ \\
\hline \multicolumn{4}{|l|}{ Number of individuals } \\
\hline All species & $46.59^{* * *}$ & $42.49^{* * *}$ & $55.78^{* * *}$ \\
\hline Predators & $40.96^{* * *}$ & 1.96 & $3.45^{*}$ \\
\hline Herbivores & $46.42^{* * *}$ & $117.22^{* * *}$ & $38.16^{* * *}$ \\
\hline Detritivores & $525.07^{* * *}$ & $11.77^{* * *}$ & $5.48^{* * *}$ \\
\hline \multicolumn{4}{|l|}{ Number of species } \\
\hline Total number of species & $6.43^{*}$ & 0.14 & 1.46 \\
\hline Predators & $28.46^{* * *}$ & $4.39^{*}$ & 1.66 \\
\hline Herbivores & $29.25^{* * *}$ & 0.13 & $4.75^{* *}$ \\
\hline Detritivores & $24.34^{* * *}$ & 0.19 & 0.63 \\
\hline
\end{tabular}

Note: ${ }^{*{ }^{* *}}{ }^{*}$ and ${ }^{* * *}$ indicate significance at $P<0.05, P<0.01$ and $P<0.001$, respectively. 

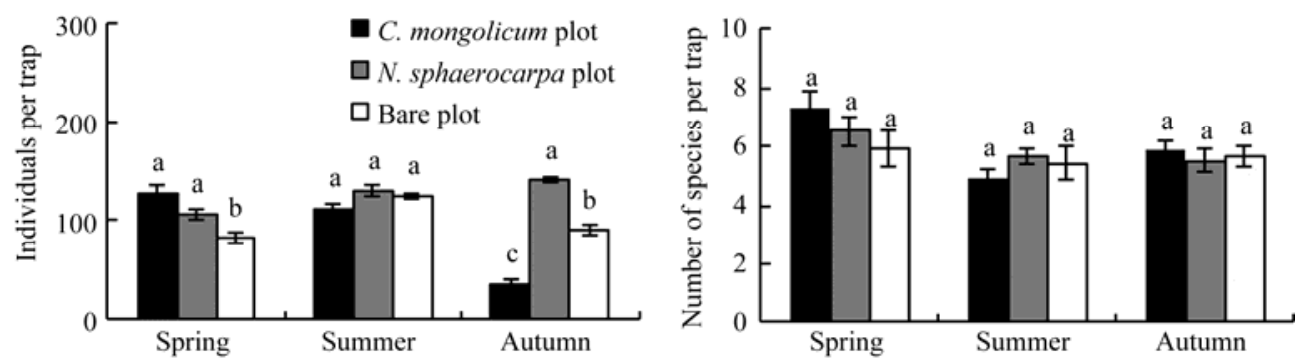

Fig. 1 The effects of season and plot type on the abundance and richness of ground beetles. Different letters indicate significant differences between plots within each sampling period ( $P<0.05$ from Tukey's HSD tests). Vertical bars represent mean \pm SE.

\subsection{Trophic-level responses to the presence and species of shrubs}

The Carabidae, Curculionidae and Tenebrionidae captured in the study sites primarily included generalist predators, herbivores and detritivores, respectively (Table 1). The abundance of predators was not affected by plot type, but the richness of predators was strongly affected by plot type (Table 2). The abundances of detritivores and herbivores were strongly
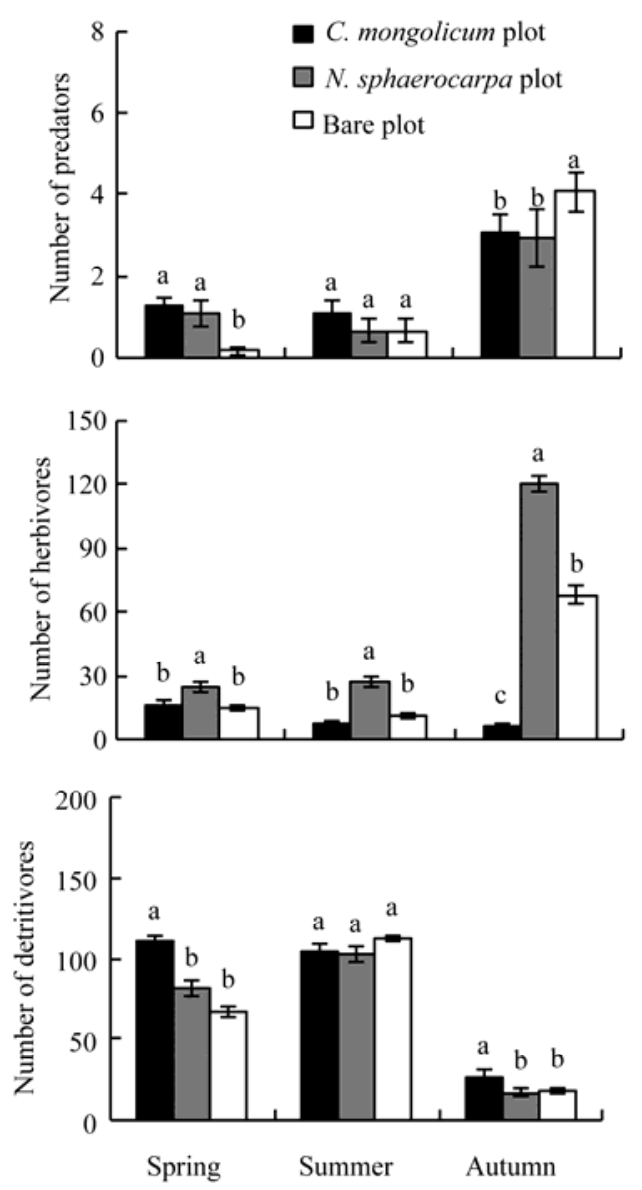

affected by season and plot type, and the significant interaction between season and plot type was observed, but the richness of detritivores and herbivores was not affected by plot types (Table 2). Separate analyses for each season on predators showed that the positive effects on their abundance and richness occurred only in spring, whereas a negative effect of shrubs on their abundance of predators was observed in autumn (Fig. $2)$. Separate analyses for each season on the
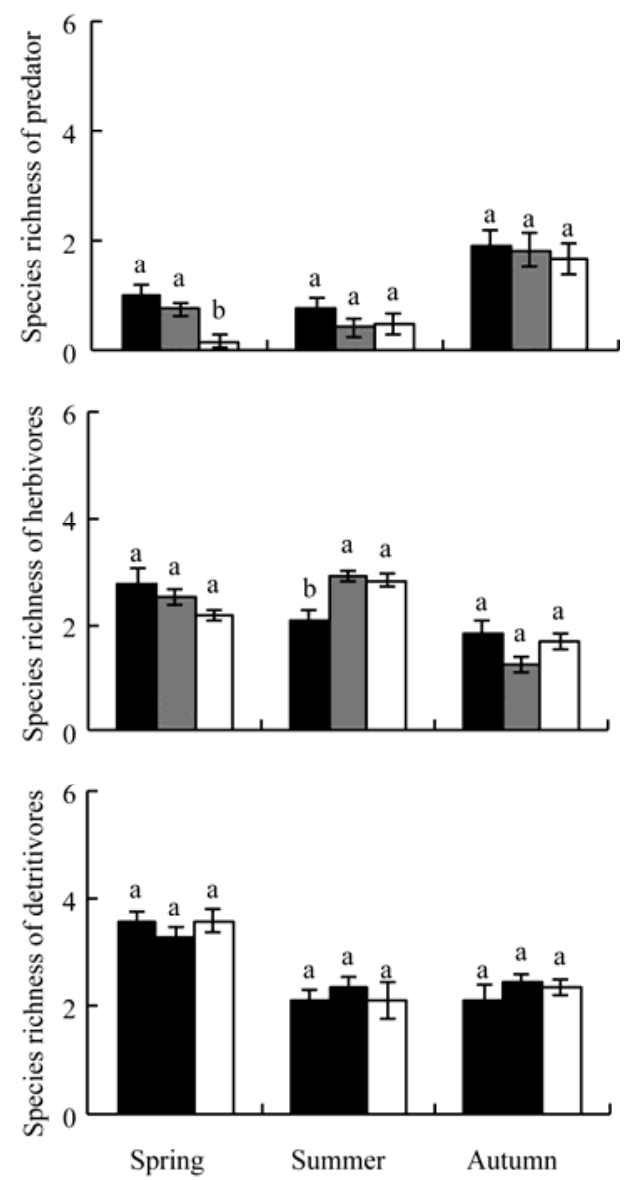

Fig. 2 The effects of season and plot type on the abundance and richness of three trophic groups. Different letters indicate significant differences between plots within each sampling period ( $P<0.05$ from Tukey's HSD tests). Vertical bars represent mean \pm SE. 
herbivores showed that the identity of shrub species affected the abundance of herbivores in spring, summer and autumn, and a similar pattern was also found on the richness of the herbivores in summer (Fig. 2). More herbivores were captured in sphaerocarpa than in mongolicum plots, but this pattern appeared to be significant only in summer (Fig. 2). Separate analyses for each season on the detritivores showed that the identity of shrub species affected the abundance of detritivores in spring and autumn (Fig. 2). In addition, significantly greater numbers of detritivores were captured in the mongolicum than in the sphaerocarpa plots (Fig. 2).

\subsection{Species-level responses to the presence and species of shrubs}

Seven out of eight of the dominant species responded significantly to the presence and species of shrubs. Carabus sp., Curculionidae sp. 1, Tentyria sp. and Microdera sp. were strongly affected by season and plot type, and there was a significant interaction between season and plot type (Table 3). Blaps gobiensis, Cyphogenia chinensis and Sternoplax setosa were strongly affected by season and plot type (Table 3). Separate analyses for each season showed that the positive effect of shrubs on the abundance of $\mathrm{Mi}$ crodera sp. was significant only in spring, while the negative effect of shrubs on the abundance of Carabus sp. was observed only in autumn. Separate analyses for each season showed that the identity of shrub species significant affected the abundances of Blaps gobiensis, Carabus sp., Curculionidae sp.1, Cyphogenia chinensis, Sternoplax setosa and Tentyria sp. (Fig. 3).
A greater number of Blaps gobiensis was captured in spring, Carabus sp. was commonly captured in autumn, and Tentyria sp. had an abundance peak in spring and autumn. The latter species was also more frequently captured in mongolicum plots than in the sphaerocarpa plots, and an opposite pattern was observed for Cyphogenia chinensis in all sampling periods, Sternoplax setosa in spring and summer, and Curculionidae sp. 1 in summer and autumn.

\section{Discussion}

This study provides the first investigation of the influence of shrub presence and species identity on the distribution and diversity of ground beetle communities in a sandy desert of northwestern China. The study highlights the roles of C. mongolicum and $N$. sphaerocarpa shrub patches as 'keystone structures' (Tews et al., 2004) and 'bug islands' (Zhao and Liu, 2013) in the studied ecosystem. The findings are consistent with those of studies on other desert ecosystems, which demonstrated that shrubs facilitate the aggregation of soil and ground arthropods, resulting in higher density and species richness of these arthropods under the shrub canopy than in open areas (Rogers et al., 1988; Stapp, 1997; Peterson et al., 2001; Mazía et al., 2006; Doblas-Miranda et al., 2009; Liu et al., 2012; Li et al., 2013; Zhao and Liu, 2013).

The two shrub species were associated with different catch rates of all ground beetles, herbivores and detritivores and six abundant species. This result is only partially consistent with those of Peterson et al.

Table 3 Results of two-way ANOVA for the effects of season (spring, summer and autumn) and plot type (C. mongolicum, N. sphaerocarpa and bare plot) and their interactions on the abundance of abundant species

\begin{tabular}{|c|c|c|c|}
\hline & Season $\left(F_{2,107}\right)$ & Plot type $\left(F_{2,107}\right)$ & Season $\times$ Plot type $\left(F_{4,107}\right)$ \\
\hline Anatolica sp. & $8.97^{* * *}$ & 0.88 & 0.52 \\
\hline Blaps gobiensis & $25.76^{* * *}$ & $3.73^{*}$ & 1.51 \\
\hline Carabus sp. & $43.82^{* * *}$ & $6.86^{* *}$ & $6.70^{* * *}$ \\
\hline Curculionidae sp. 1 & $355.57^{* * *}$ & $122.84^{* * *}$ & $37.74^{* * *}$ \\
\hline Cyphogenia chinensis & $135.04^{* * *}$ & $7.40^{* * *}$ & 1.99 \\
\hline Sternoplax setosa & $381.85^{* * *}$ & $5.93^{* *}$ & 2.36 \\
\hline Tentyria sp. & $636.05^{* * *}$ & $14.40^{* * *}$ & $6.18^{* * *}$ \\
\hline Microdera sp. & $26.48^{* * *}$ & $7.07^{* * *}$ & $3.84^{* *}$ \\
\hline
\end{tabular}



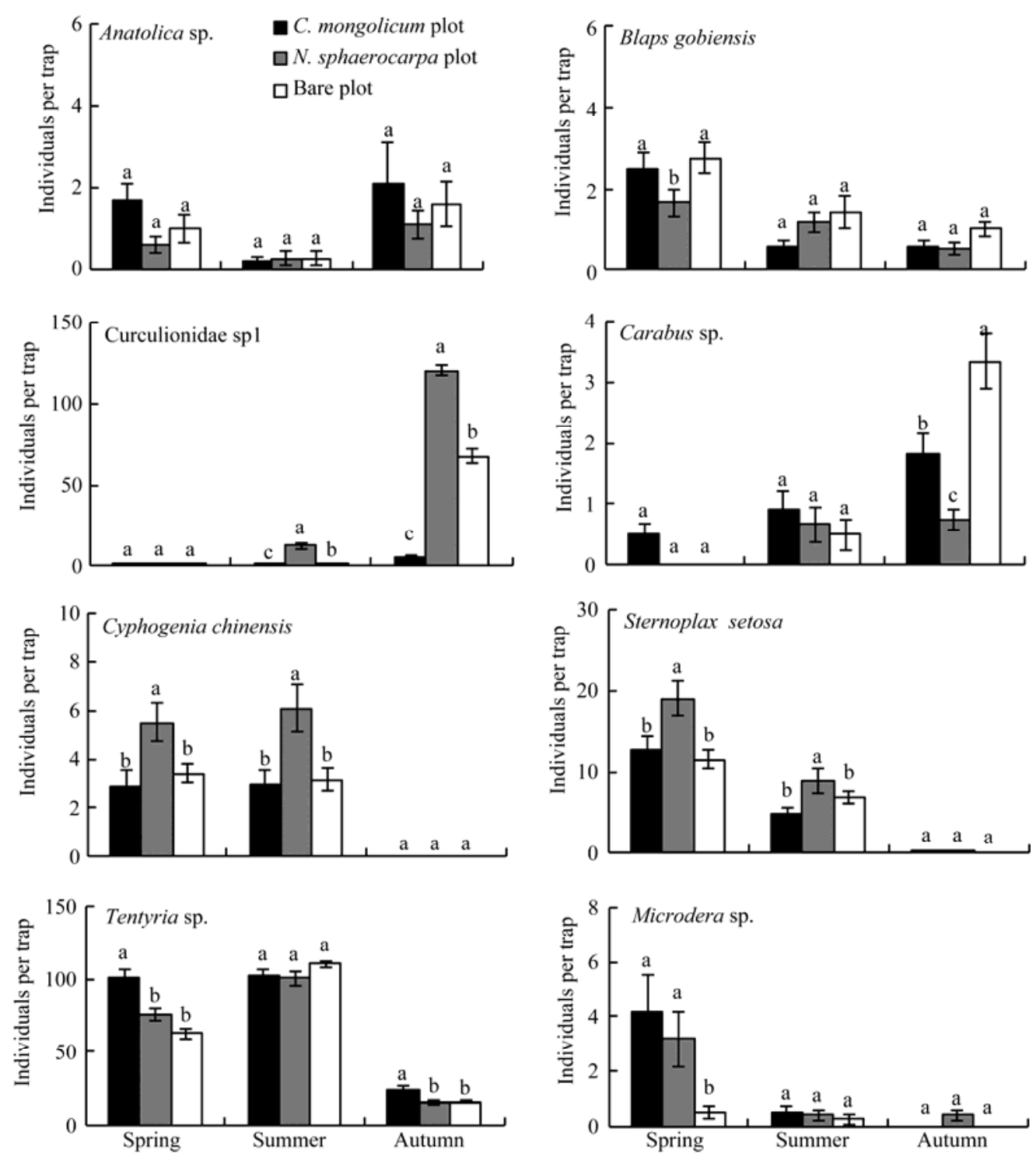

Fig. 3 The effects of season and plot type on the activity density and species richness of eight domain species. Different letters indicate significant differences between plots within each sampling period ( $P<0.05$ from Tukey's HSD tests). Vertical bars represent mean \pm SE.

(2001), Doblas-Miranda et al. (2009) and Liu et al. (2012). Peterson et al. (2001) observed differences in earthworm abundance among four shrub species in a Southern Californian chaparral ecosystem, but these shrubs did not differ in litter-active macrofauna. Similarly Doblas-Miranda et al. (2009) reported differences in the diversity, abundance and biomass of soil macrofauna among three shrub species (Artemisia herba-alba Asso, Retama sphaerocarpa L. and Salsola oppositifolia Desf) in a Mediterranean arid ecosystem. In addition, Liu et al. (2012) reported significant differences in beetle abundance and richness between two shrub species (Nitraria sphaerocarpa and Reau- muria soongorica) in a Gobi desert ecosystem. The above studies suggest that different soil and ground-dwelling faunal groups or communities respond differently to various shrub species. The observed differences in the response of ground arthropods to the two shrub species may be explained by the differences in the morphological, chemical and phenological traits between the shrub species (Whitham et al., 1999), as well as the differences in resource quantity and quality which both shrub species provide (Wilder et al., 2011). According to the data of the present study, the two shrub species differ in many aspects. First, an adult individual of $C$. mongolicum is 
generally larger in size than that of $N$. sphaerocarpa. Larger sized plants may contribute more resources (plant litter: 11.1 and $5.1 \mathrm{~g} / \mathrm{kg}$, respectively) to herbivore and decomposer beetles, and may also provide greater numbers of secure oviposition sites for beetles than that of smaller-sized plants (Stapp, 1997). Second, the leaves of $N$. sphaerocarpa have higher nitrogen content than that of C. mongolicum (22.2 and $9.2 \mathrm{~g} / \mathrm{kg}$, respectively). Third, both shrubs differed considerably in their phenological characteristics. For example, $C$. mongolicum germinates in early April, blossoms in May-July, and fruits in June-August, whereas $N$. sphaerocarpa germinates in mid-April, blossoms in mid-May, and fruits in June. This phonological difference may reflect differences in the growth pattern of the shrubs with regard to the seasonal dynamics of leaf biomass and quality. As much, large plant size, the high leaf production of $C$. mongolicum and high leaf-nitrogen content of $N$. sphaerocarpa may explain why many species of beetles (Blaps gobinesis, Carabus sp. and Tentyria sp.) preferred C. mongolicum plants, while few beetles (Curculionidae sp.1, Cyphogenia chinensis and Sternoplax setosa) preferred $N$. sphaerocarpa plants.

Furthermore, we also found that the activity density of ground-dwelling beetles was strongly affected by season, which is in accordance with other studies (Stapp, 1997; Sackmann and Flores, 2009; Liu et al., 2012; Li et al., 2013). Shrub presence had a strong effect on the total abundance of individuals in spring, but an opposite trend was found in autumn, along with a strong shrub species effect on total abundance of individuals. These season-specific responses indicate that the influence of shrub presence and species on beetle abundance and richness is strongly altered by the seasonal dynamics of both beetles' composition and feeding activity and resource availability (Lövei and Sunderland, 1996; Stapp, 1997; Zotov and Alpatov, 2005; Sackmann and Flores, 2009). Analysis of the captures of the eight most common species revealed that shrub presence and species did not differ among spring, summer and autumn. First, there was one species that showed no obvious affinities for a particular microhabitat, i.e. Anatolica sp., for which most of the abundances were captured in spring and autumn. Second, Microdera sp. was the only beetle that was most often captured in spring; this species was abundantl under the shrubs. Third, for Blaps gobiensis, Tentyria sp., Cyphogenia chinensis and Sternoplax setosa, most of the beetles were captured in the spr or summer, the two species showed obvious affinities for C. mongolicum microhabitat, and the other two species showed obvious affinities for $N$. sphaerocarpa microhabitat. Fourth, for Carabus sp. and Curculionidae sp. 1, most of beetles were captured in autumn, and it was also shown that they moved between special shrub species and bare ground microhabitats. Curculionidae sp. 1 was abundant in autumn, and feed on leaf of $N$. sphaerocarpa shrubs (observed personally). Curculionidae sp. 1 may be attracted by the leaves of $N$. sphaerocarpa shrubs, and moves between $N$. sphaerocarpa shrubs which result in few Curculionidae sp. 1 captured under C. mongolicum shrubs. For Carabus sp., shrubs may provide a rich source of prey from the detrital soil web (Koivula et al., 1999; Mazía et al., 2006). Beetles may seek shrubs for thermal cover or may be attracted by the food resources accumulated under shrubs (Stapp, 1997; Mazía et al., 2006), and beetle in autumn may be attracted by the food resources due to the decrease of soil temperature and solar radiation stress. The shrub presence and species affecting the beetles in our system differed among the three seasons in the following aspects. First, the precipitation pattern affected the phonological changes and productivity of the shrubs (Richard et al., 1997; Austin et al., 2004; Sackmann and Flores, 2009; Barrows, 2012; Pozsgai and Littlewood, 2014). This phonological difference may reflect the growth pattern of the shrubs with regard to the seasonal dynamics of microhabitat production. Second, the seasonal preferences of ground beetle species to avoiding the harsh condition are determined by the physiological and reproductive adaptation selection of the appropriate activity seasons (Krasnov and Ayal, 1995; Stapp, 1997; Mazía et al., 2006; Shelef and Groner, 2011; Liu et al., 2012; Li et al., 2013). In this regard, seasonal variation of ameliorated microclimatic conditions and food available between shrubs and open habitat had been shown to strongly affect the distribution, as well as physiological and reproductive adaptations of ground beetles in desert ecosystems (Crawford, 1988; Stapp, 1997; Richard et al., 2001; 
Mazía et al., 2006; Sackmann and Flores, 2009; Shelef and Groner, 2011; Liu et al., 2012; Liu et al., 2013).

\section{Conclusions}

The purpose of this paper is to analyze the impacts of shrub presence and species on the spatial distribution of ground beetles in a sandy desert ecosystem. Shrub vegetation had a positive effect on the activity and species richness of ground beetles in spring, but an opposite pattern occurred in autumn, suggesting the presence of season-specific shrub effects on the ground beetles. Our results reveal the complexity of potential mechanisms by which shrub vegetation influences ground beetle assemblage. This complexity involves at least two important aspects. First, the influence of shrub presence and species identity on the ground beetles demonstrated season-specific signatures. This seasonality suggests that shrubs and species identity effects are strongly modulated by the seasonal dynamics of both the beetle community composition and resource availability (habitat production). Second, the influence of shrub presence and species identity on the ground beetle community demonstrated species-specific signatures. Differences observed in the activity density, species richness and composition of ground beetle communities among plot types are largely related to the among-plot differences in the microclimate environment and resource availability. These findings provide valuable information supporting the development of a regional conservation plan for the conservation of beetle diversity in this sandy desert ecosystem.

\section{Acknowledgements}

This research was funded by the National Basic Research Program of China (2013CB429903) and the National Natural Science Foundation of China (41201248, 31170496). The authors are very thankful to two reviewers for proposing good suggestions.

\section{References}

Aguiar M R, Sala O E. 1999. Patch structure, dynamics and implications for the functioning of arid ecosystems. Trends in Ecology \& Evolution, 14: 1-5.

Anderson M J, Gorley R N, Clarke K R. 2008. PERMANOVA+ for PRIMER: Guide to Software and Statistical Methods. PRIMER-E, UK: Plymouth.
Antvogel H, Bonn A. 2001. Environmental parameters and microspatial distribution of insects: a case study of carabids in an alluvial forest. Echography, 24: 470-482.

Austin A T, Yahdjian L, Stark J M, et al. 2004. Water pulses and biogeochemical cycles in arid and semiarid ecosystems. Oecologia, 141: 221-235.

Ayal Y, Merkl O. 1994. Spatial and temporal distribution of tenebrionid species (Coleoptera) in the Negev Highlands, Israel. Journal of Arid Environments, 27(4): 347-361.

Bang C, Faeth S H, Sabo J L. 2012. Control of arthropod abundance, richness, and composition in a heterogeneous desert city. Ecological Monographs, 82(1): 85-100.

Bardgett R D, Mawdsley J L, Edwards S, et al. 1999. Plant species effects on soil biological properties of temperate upland grassland. Functional Ecology, 13: 650-660.

Barrows C W. 2012. Temporal patterns of abundance of arthropods on sand dunes. The Southwestern Naturalist, 57(3): 262-266.

Bartholomew A, Ebeid K. 2011. Habitat complexity influences the microhabitat choices of desert beetles. Israel Journal of Ecology \& Evolution, 57(3): 213-221.

Barton P S, Manning A D, Gibb H, et al. 2009. Conserving ground-dwelling beetles in an endangered woodland community: multi-scale habitat effects on assemblage diversity. Biological Conservation, 142: 1701-1709.

Ben-Natan G, Abramsky Z, Kotler B P, et al. 2004. Seeds redistribution in sand dunes: a basis for coexistence of two rodent species. Oikos, 105(2): 325-335.

Bezemer T M, Fountain M T, Barea J M, et al. 2010. Divergent composition but similar function of soil food webs beneath individual plants: plant species and community effects. Ecology, 91: 3027-3036.

Botes A, McGeoch M A, Chown S L. 2007. Ground-dwelling beetle assemblages in the northern Cape Floristic Region: Patterns, correlates and implications. Austral Ecology, 32(2): 210-224.

Bullock J M, Moy I L. 2004. Plants as seed traps: inter-specific interference with dispersal. Acta Oecologica, 25(1): 35-41.

Cloudsley-Thompson J L. 2001. Thermal and water relations of desert beetles. Naturwissenschaften, 88: 447-460.

Crist T O, Pradhan-Devare S V, Summerville K S. 2006. Spatial variation in insect community and species responses to habitat loss and plant community composition. Oecologia, 147: 510-521.

Doblas-Miranda E, Sánchez-Piñero F, González-Megías A. 2009. Different microhabitats affect soil macroinvertebrate assemblages in a Mediterranean arid ecosystem. Applied Soil Ecology, 41(3): 329-335.

Eldridge D J, Bowker M A, Maestre F T, et al. 2011. Impacts of shrub encroachment on ecosystem structure and functioning: towards a global synthesis. Ecology Letters, 14(7): 709-722.

Fallaci M, Colombini I, Palesse L, et al. 1997. Spatial and temporal strategies in relation to environmental constraints of four tenebrionids inhabiting a Mediterranean coastal dune system. Journal of Arid Environments, 37: 45-64.

Gaston K J. 1991. The magnitude of global insect species richness. Biological Conservation, 5: 283-296.

Gobbi M, Fontaneto D. 2008. Biodiversity of ground beetles (Coleoptera: 
Carabidae) in different habitats of the Italian Po lowland. Agriculture, Ecosystems \& Environment, 127: 273-276.

Haworth K, McPherson G R. 1995. Effects of Quercus emoryi on precipitation distribution and microclimate in a semi-arid savanna. Journal of Arid Environments, 31: 153-170.

He Q, Wang X P, Yang G J. 2011. Species diversity of carabid beetles in desert-steppe in Yanchi of Ningxia, China. Acta Ecologica Sinica, 31(4): 923-932 (In Chinese).

Krasnov B, Ayal Y. 1995. Seasonal changes in darkling beetle communities (Coleoptera: Tenbrionidae) in the Ramon Erosion Cirque Negev Highlands, Israel. Journal of Arid Environments, 31: 335-347.

Kremen C, Colwell R K, Erwin T, et al. 1993. Terrestrial arthropod assemblages: their use in conservation planning. Biological Conservation, 7: 796-808.

Lawrence J F, Britton E B. 1991. Coleoptera (beetles). In: CSIRO. Insects of Australia. A Textbook for Students and Research Workers, Melbourne: Melbourne University Press, 543-683.

Li F R, 2008. Presence of shrubs influences the spatial pattern of soil seed banks in desert herbaceous vegetation. Journal of Vegetation Science, 19(4): 537-548.

Li F R, Liu J L, Liu C A, et al. 2013. Shrubs and species identity effects on the distribution and diversity of ground-dwelling arthropods in a Gobi desert. Journal of Insect Conservation, 17(2): 319-331.

Liu J L, Li F R, Liu Q J, et al. 2010. Seasonal variation in soil fauna community composition and diversity in an arid desert ecosystem of the Heihe Basin. Journal of Desert Research, 30: 342-349 (in Chinese).

Liu J L, Li F R, Liu C A, et al. 2012. Influences of shrub vegetation on distribution and diversity of a ground beetle community in a Gobi desert ecsystem. Biodiversity and Conservation, 21: 2601-2619.

López-Pintor A, Gómez Sal A, Benayas J M R. 2006. Shrubs as a source of spatial heterogeneity: the case of Retama sphaerocarpa in Mediterranean pasture of central Spain. Acta Oecologica, 29: 247-255.

Lövei G L, Sunderland K D. 1996. Ecology and behavior of ground beetles (Coleoptera: Carabidae). Annual Review of Entomology, 41: 231-256.

Mazía C N, Chaneton E J, Kitzberger T. 2006. Small-scale habitat use and assemblage structure of ground-dwelling beetles in a Patagonian shrub steppe. Journal of Arid Environments, 67: 177-194.

Moore J C, Berlow E L, Coleman D C, et al. 2004. Detritus, trophic dynamics and biodiversity. Ecology Letters, 7(7): 584-600.

Parmenter R R, Macmahon J A. 1988. Factors limiting populations of arid-land darkling beetles (Coleoptera: Tenebrionidae): predation by rodents. Environmental Entomology, 17(2): 280-286.

Parmenter R R, Parmenter C A, Cheney C D. 1989. Factors influencing microhabitat partitioning among coexisting species of arid- land darkling beetles (Tenebrionidae): behavioral responses to vegetation architecture. The Southwestern Naturalist (USA), 34: 319-329.

Peterson A C, Hendrix P F, Haydu C, et al. 2001. Single-shrub influence on earthworms and soil macroarthropods in the southern California chaparral. Pedobiologia, 45: 509-522.

Pétillon J, Georges A, Canard A, et al. 2008. Influence of abiotic factors on spider and ground beetle communities in different salt-marsh systems. Basic and Applied Ecology, 9: 743-751.

Polis G A. 1991. The Ecology of Desert Communities. Tucson: The University of Arizona Press.

Pozsgai G, Littlewood N A. 2014. Ground beetle (Coleoptera: Carabidae) population decline sand phenological changes: Is there a connection?. Ecological Indicators, 41: 15-24.

Ren G D, Yu Y Z. 1999. The Darking Beetles from Deserts and Semi-Deserts of China (Coleoptera: Tenebrionidae). Baoding: Hebei University Publishing House. (in Chinese)

Reynolds J F, Smith D M S, Lambin E F, et al. 2007. Global desertification: building a science for dryland development. Science, 316(5826): 847-851.

Richard J D, Salazar J R, Guo Y J. 2001. A darkling beetle population in West Texas during the 1997-1998 El Niño. Journal of Arid Environments , 49: 711-721.

Rogers L E, Woodley N E, Sheldon J K, et al. 1988. Diets of darkling beetles (Coleoptera: Tenebrionidae) within a shrub-steppe ecosystem. Annals of the Entomological Society of America, 81: 782-791.

Rykken J J, Capen D E, Mahabir S P. 1997. Ground beetles as indicators of land type diversity in the Green Mountains of Vermont. Conservation Biology, 11(2): 522-530.

Sackmann P, Flores G E. 2009. Temporal and spatial patterns of tenebrionid beetle diversity in NW Patagonia, Argentina. Journal of Arid Environments, 73: 1095-1102.

Sanchez B C, Parmenter R R. 2002. Patterns of shrub-dwelling arthropod diversity across a desert shrubland grassland ecotone: a test of island biogeographic theory. Journal of Arid Environments, 63: 247-265.

Schlesinger W H. 1991. Biogeochemistry: An Analysis of Global Change. San Diego: Academic Press.

Shelef O, Groner E. 2011. Linking landscape and species: Effect of shrubs on patch preference of beetles in arid and semi-arid ecosystems. Journal of Arid Environments, 75: 960-967.

Stapp P. 1997. Microhabitat use and community structure of darkling beetles (Coleoptera: Tenebrionidae) in shortgrass prairie: effects of season, shrub cover and soil type. American Midland Naturalist, 137: 298-311.

Tews J, Brose U, Grimm V, et al. 2004. Animal species diversity driven by habitat heterogeneity/diversity: the importance of keystone structures. Journal of Biogeography, 31(1): 79-92.

Valiente-Banuet A, Ezcurra E. 1991. Shade as a cause of association between the cactus Neobuxbaumia tetetzo and the nurse plant Mimosa luisana in the Tehuacán Valley, Mexico. Journal of Ecology, 79: 961-971.

Watson D M, McGregor H W, Spooner P G. 2011. Hemiparasitic shrubs increase resource availability and multi-trophic diversity of eucalypt forest birds. Functional Ecology, 25(4): 889-899.

Whitham T G, Martinsen G D, Floate K D, et al. 1999. Plant hybrid zones affect biodiversity: Tools for a genetic-based understanding of community structure. Ecology, 80: 416-428.

Wilder S M, Holway D A, Suarez A V, et al. 2011. Macronutrient content of plant-based food affects growth of a carnivorous arthropod. Ecology, 92: 325-332. 
Woodcock B A, Pywell R F, Roy D B. 2005. Grazing management of calcareous grasslands and its implications for the conservation of beetle communities. Biological Conservation, 125: 193-202.

Yang G J, He Q, Wang X P. 2010. Darkling beetle community structure and its relations with environmental factors in Sidunzi of Yanchi, Ningxia, China. The Journal of Applied Ecology, 21(9): 2375-2382 (in Chinese).

Yin X Q, Song B, Dong W H, et al. 2010. A review on the eco-geography of soil fauna in China. Journal of Geographical Sciences, 20(3): 333-346.

Zhang D Z, Zhang F J, Yu Y Z. 2003. Preliminary study on the behavior of six species of Tenebrionidae. Journal of Ningxia University:
Natural Science Edition, 1: 94-96. (in Chinese)

Zhao H L, Zhou R L, Su Y Z, et al. 2007. Shrub facilitation of desert land restoration in the Horqin Sand Land of Inner Mongolia. Ecological Engineering, 31(1): 1-8.

Zhao H L, Liu R T. 2013. The "bug island" effect of shrubs and its formation mechanism in Horqin Sand Land, Inner Mongolia. Catena, 105: 69-74.

Zheng L Y, Gui H. 1999. Classification of Insects in China. Nanjing: Nanjing Normal University Publishing. (in Chinese)

Zotov V A, Alpatov A M. 2005. Adaptive significance of the circadian rhythm of activity in omniseasonal desert beetles (Coleoptera, Tenebrionidae). Entomology Review, 85: 357-360. 